\title{
Analysis of the zinc covering quality formed by the vibration chemical-mechanical synthesis
}

\author{
Vladimir Ivanov ${ }^{1}$, Valeriy Lebedev ${ }^{1,}{ }^{*}$, Irina Davydova ${ }^{1}$, Tatiana Atoyan ${ }^{1}$ \\ ${ }^{1}$ Don State Technical University, Rostov-on-Don, Russia
}

\begin{abstract}
The analysis of the results of experimental studies of production of zinc coverings by the way of vibration chemical and mechanical synthesis words.
\end{abstract}

The specific of formation of a zinc covering in vibration technological systems is that in the conditions of dynamic influence of the free moving metal or glassy indenters, activation of all components of the elements participating in formation of a covering is sharply increased. Molecules and atoms gain the padding energy which promoet overcome the potential hill influencing on the speed of chemical reactions. Catalytic properties are given to the surfaces of material relation to the reaction of restitution of ions of a double electric layer with the established equilibrium potential. In the result in the boundary layer, electrolytic potential in relation to equilibrium is displaced up to the sizes at which the reaction of restitution of ions of zinc' ions is possible.

The solid bodies which are immediately participating in chemical and mechanical process of formation of a zinc covering always have the ability to absorb in a varying degree (to adsorb) from environment on the surface molecules, atoms or ions. [1]. The numerous researches in this area led to a number of interesting conclusions for many almost important processes.

For the right understanding of adsorption process it is necessary to consider that various atoms of the surface layer of metal adsorbent are not in identical conditions. It occurs because the surface of a solid body is not smooth, but has numerous micro roughness. At the atoms located on various sites of a surface the degree of saturation of valence forces is various, therefore, also their ability to the interaction with atoms and molecules from solution or environment is not identical. The most fissile section of a surface do not adsorb the molecule from solution any more, and its chemical properties have the initial value, i.e. adsorption in this case is specific. [2,3].

In the process of the chemical and mechanical synthesis operated by power influence of vibration system, the surface of metal is exposed to numerous multidirectional blows, elasto-plastic deformation and, as a result, activation of the surface; at the same time such phenomena as adsorption and diffusion are talien place [4].

At the first moment of formation of a covering Zincum ion, from solution passed a double layer, exempted from a hydrated envelope, is adsorbed on the fissile surfaces of ledges. Here Zincum ion $(\mathrm{Zn}++)$ is discharged (accepts electrons) and $(\mathrm{Zn})$ is besieged on the surface of metal at the expense of an oxidizing the restored processes in the form of a zinc covering. The formation of the first crystals of the besieged metal leads to the emergence of the micro/nano covering metal elements. As a result on a potential difference of $\mathrm{Fe}-\mathrm{Zn}$ the field of minerals is imposed. The increase of an internal energy of the surface layers of metal, as a result of elasto-plastic deformation, leads to increase in the adsorption activity of a metal surface, ion activity and molecules, increase in crystallization centers and, density of micro currents. At the same time in the surface layer the micro/nano structures of a nucleus of a zinc covering are formed, at the same time appearing EMF has significant effect on further body height of a covering. The formation of crystalline structures of a covering happens not only on ledges, but also on sides, and in deepenings of a microprofile of a surface. As a result metal is covered more evenly, crystals are closed, forming an intact coating [5].

The research of micro and nano structure of a surface of a zinc covering on sampels from carbon steel shown that the covering received as a result of vibration chemical and mechanical synthesis possesses chaotically focused surface morphology where the open sections of a zinc covering are $\approx 100$ microns (Fig. 1a). At the scale of 10 microns it is visible that on border of large sections of a covering structures of 2-5 microns in size are created (the allocated sections in Fig. 3b). In Fig. 1d the arrow shows the structure of a covering of the transition zone consisting of crystals from 1 micron in size. The increasing of this section up to the scale of 1 micron, shows the change of morphology and appearing on the top of a crystal of communications in the form of threads of $0,2-0,5$

\footnotetext{
*Corresponding author: va.lebidev@yandex.ru
} 
microns in size. A rescaling up to 200 nanometers (Fig. 3e) allowed to establish the amount of intercrystal communications and the sizes of separate elements ranging from 50 up to 100 nanometers. In Fig. $3 \mathrm{~g}$ the scale of 100 nanometers intercrystal communications and separate crystals of a covering at a background in the form of light oval sites clearly are visible. Perhaps to receive such character of an arrangement of crystals of zincum in a covering only is the result of vibration influence.

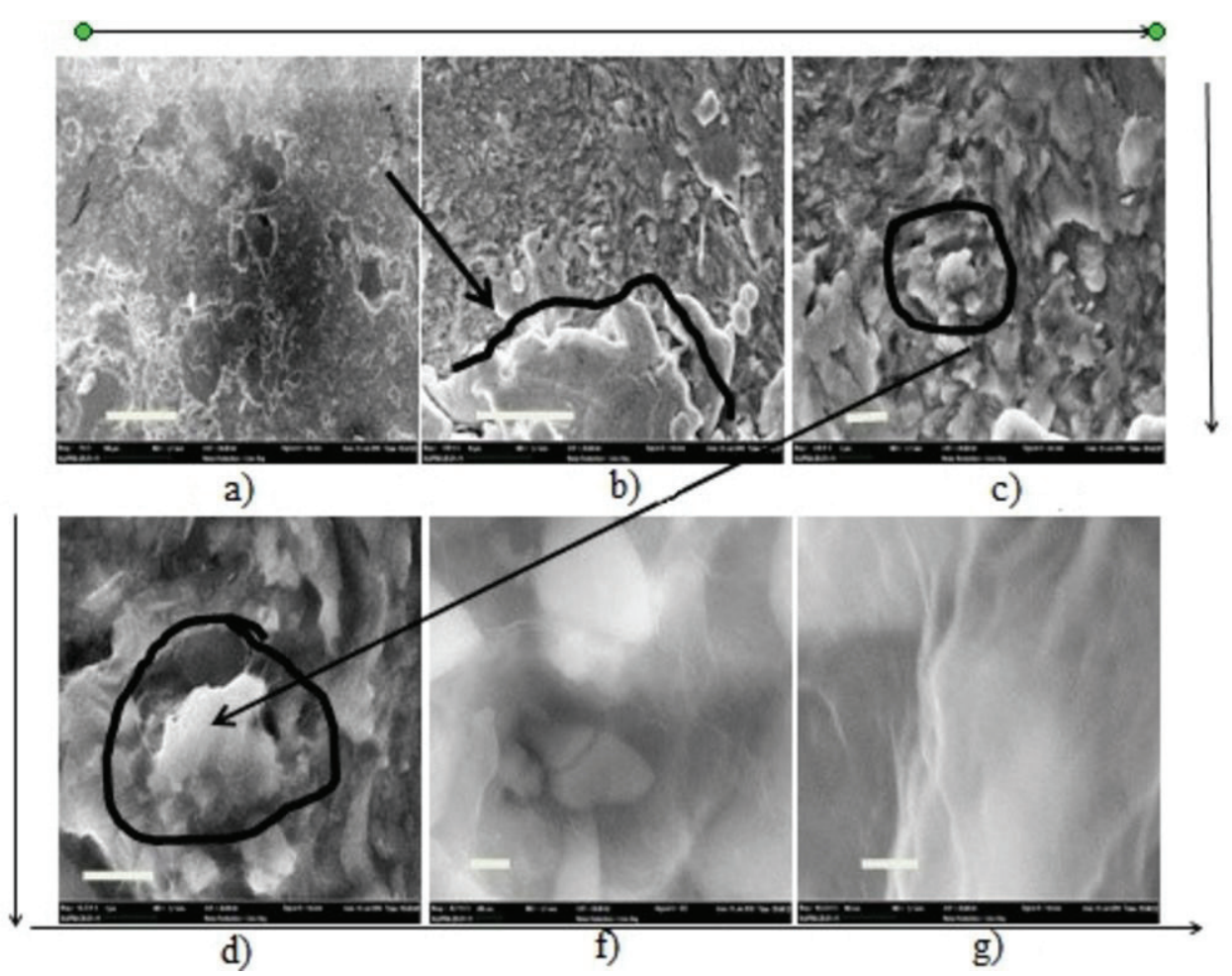

Fig. 1. The morphology of a surface of a zinc covering received by vibration of mechanical - chemical synthesis at various increase ( $\mathrm{a}$ - the scale of 100 microns, b- scale is 10 microns, c - scale is 2 microns, $\mathrm{d}$ - scale is 1 micron, e -scale is 200 nanometers, g-scale is 100 nanometers) and a process conditions: amplitude of fluctuation of the building bag of $\mathrm{A}=3,5 \mathrm{~mm}$, frequency $f=33,3 \mathrm{~Hz}$, time $\mathrm{t}=$ 60 min., actuation medium porcelain spheres $\mathrm{D}=3-10 \mathrm{~mm}$., working solution of chloride zincum - $250 \mathrm{~g} / \mathrm{l}$, zincum powder $-100 \mathrm{~g} / \mathrm{l} /$.

The layer of a zinc covering formed in an incipient state is a basis for the subsequent its body height, it is very important to provide the maximal activity of a surface. The formation of a large number of shallow crystals provides more complete overlapping of the main metal. The smaller porosity, the increased rust resistance and larger anchoring strength with the main metal is a reached as the result.

In Fig. 2 the electronic image of texture of the covering received in the course of vibration chemical and mechanical synthesis and a galvanic way is submitted. The structure of galvanic zinc coverings is porous, the sharp border dividing metal and a covering is observed, the micro emptiness on all surfaces of a micro section which existence does not promote giving to a covering of high corrosion behavior [6] are legibly expressed. Unlike them forthe tightly paked structure with lack of sharp border between metal and a covering is characteristic of the zinc coverings received in the course of vibration chemical and mechanical synthesis, thickness of a covering reaches 30-40 microns, the covering and the substrate have the identical metal nature the navodorozhenny layer inherent to isabsent.

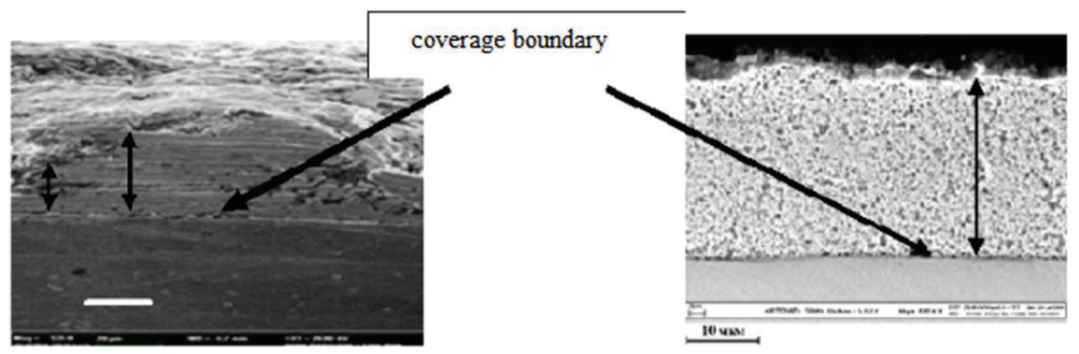

a)

b)

Fig.2. A micro section of the zinc covering received:

a) vibration chemical and mechanical synthesis, micron scale-20; b) - in the galvanic way, micron scale-10. 
One of key indicators of quality of zinc coverings is rust resistance. In Fig. 3 the results of corrosion tests in the camera of salty fog within 20 days are presented, it is model from steel of St 3 with a zinc covering, put in the course of vibration chemical and mechanical synthesis-1 and a galvanic way-2. In the a result of corrosion tests are established: the zinc covering created by vibration chemical and mechanical synthesis surpasses the zinc covering received by a traditional method by 1,7-2,0 times in rust resistance; destruction of zinc coverings is influenced by porosity: than less thickness of a covering, subjects it is higher that promotes more mild penetration a severe atmosphere to the main metal.

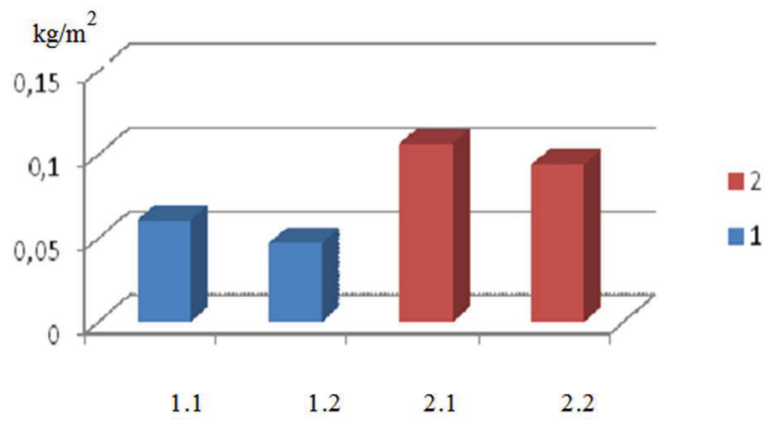

Fig. 3. Change of corrosion rate of a zinc covering depending on a method of drawing and its thickness:1.1-6 microns.; 1.2 - 14 microns.; 2.1-6 microns., 2.2 - 14 microns.

\section{Conclusions}

The carried-out analysis confirms the effectiveness of receiving zinc coverings by the way of vibration chemical and mechanical synthesis. As the main advantages in comparing with traditional methods of their drawing, it is possible to allocate: combination of processes of deposition and machining of a surface; simplicity of a design of an inventory owing to lack of current lead; lack of a hydrogen charging of the surface layer; a possibility of the covering "difficult covered" metals; use of a trace amount of electrolyte; less rigid conditions to a surface pre-treatment.

\section{References}

1. A.P. Babichev, V.V. Ivanov, S.N. Hudalya, P.D. Motrenko, Yu. P. Ankudimov, I.A. Babichev, A vibration mechanochemistry in processes of the finishing strengthening processing and coverings of details of cars (monograph), 204 (DGTU publishing center, Rostov n / D, 2012)

2. A.P. Babichev, V.V. Ivanov, V.E. Burlakova, O.S. Filipchuk. Uprochnyayushchiye tekhnologii i pokrytiya, No. 7, 46-49 (2014) [in Russian]

3. V.V. Ivanov, Vibration mechanochemical coating (monograph), ISBN 978-3-659-49674-5, (LAMBERT Academic Publishing, Saarbrucken, Germany, 2014)
4. V. A. Lebedev, V. V. Ivanov and V.P. Fedorov, IOP Conf. Series: Materials Science and Engineering, 124 (2016)

5. V.V. Ivanov, G.A. Galchenko, Avtomobilnaya Promyshlennost, № 2, 30-32 (2016)

6. V.V. Ivanov, N.S. Dontsov, A.V. Kirichek, Key Engineering Materials, 736, 105-109 (2017)

7. V.V. Ivanov, S.N. Popov, V. Yu. Marchenko and E. V. Marchenko, Mir gal'vaniki, 1(29), 34-38 (2015) [in Russian]

8. V.A. Lebedev, V.V. Ivanov, S.Y. Stine and I.V. Davydova, Uprochnyayushchiye tekhnologii i pokrytiya, 8, 19-23 (2015) [in Russian]

9. V.V. Ivanov and G.A. Galchenko, Automobile Industry (2016)

10. E.A. Afanasiev and V.I. Serebryakovsky, Bulletin of Kursk State Agricultural "Agroengineering" Academy" (2014)

11. V.V. Ivanov, V.Ju. Valyavin, S.I. Popov, Ju. V. Marchenko and E.V. Marchenko, Mir gal'vaniki (2015)

12. David A. Davidson, Metal Finishing, 106, Iss. 5, 30-34 (2008)

13. LRK Gillespie, Mass Finishing Handbook, (Industrial Press, 2006)

14. W. Nebiolo, Loading vibratory finishing bowls for optimal quality, Gardner Business Media, Inc., 78, iss. 06, ISSN 0032-9940/82, 26-29 (2014)

15. A.V. Kirichek, D.L, Solovyev, A.G. Lazutkin, Technology and equipmentstatistical-width surface treatment plastic deformation (monograph), 282287 (92 n.). (Engineering, Moscow, 2004) 